\title{
Research on the design of cultural and creative products of traditional dripping animals in Southern Fujian
}

\author{
Zhong Zengqi1,a, Li Wentao ${ }^{2, b}$ \\ ${ }^{1}$ Department of Art and Design, The Jimei university, Jimei, Xiamen,Fujian, China \\ ${ }^{2}$ Department of Art and Design, The Jimei university, Jimei , Xiamen,Fujian, China \\ a410349517@qq.com \\ b*284980060@qq.com
}

\begin{abstract}
Based on the cultural value of Dishui beast, this paper carries out design research, compares its cultural value with the typical Dishui beast cultural and creative product design existing in the current cultural and creative market, and puts forward a new Dishui beast cultural and creative design strategy in view of the current deficiencies of Dishui beast cultural and creative products in the design level, in order to optimize the artistic expression of Dishui beast cultural and creative products and better show the unique characteristics The beauty of "dripping beast culture".
\end{abstract}

Keywords: Minnan Culture;Dripping beast culture; Cultural and creative products; Cultural values ; Brand; Strategy

\section{闽南传统滴水兽文创产品设计研究}

\author{
钟锃琦 ${ }^{1,}$ a李文涛 ${ }^{2, b *}$
}

${ }^{2}$ 集美大学美术与设计学院, 集美, 厦门, 福建, 中国

2 集美大学美术与设计学院, 集美, 厦门, 福建, 中国

a410349517@qq.com

b*284980060@qq.com

摘要:

文章基于滴水兽的文化价值展开设计研究，以其文化价值比照目前文创市场所存的典型滴水兽文创产品设计， 并针对当下滴水兽文创产品在设计层面的不足之处，提出滴水兽文创设计新策略，以期优化滴水兽文创产品的 艺术表达，更好的展现独特的 “滴水兽文化”之美。

关键词: 闽南文化；滴水兽文化；文创产品；文化价值；品牌；策略.

\section{1. 前言}

闽南地区的滴水兽常见于闽南传统番仔楼建筑 中，缘起于西方教堂中的滴水兽形象，是中西文化的 结晶。在闽南地区, 滴水兽作为一种流传甚广的建筑 样式, 以其特有的功能价值、精神价值、美学价值, 共同构成别具特色的 “滴水兽文化。泉州作为闽南地 区的重要城市, “滴水兽文化” 对泉州文化具有影响 作用, 特别是在 2021 年 7 月 25 日, 在福州举行的联 合国教科文组织第 44 届世界遗产委员会会议上,
“泉州: 宋元中国的世界海洋商贸中心” 被正式列入 《世界遗产名录》之中。“滴水兽文化” 作为 “泉 州文化” 的一个分支，其特质鲜明的文化属性自然也 成为文创人孵化的对象。纵观近年来产出的滴水兽文 创产品, 可见许多不同以往的设计亮点, 有的设计很 好的阐释“滴水兽文化” 的内核, 有的设计则依旧 “走 老路”, 同质化严重, 如何设计才能有推陈出新之效? 本文将对当下文创市场上滴水兽产品的设计进行比 对分析, 了解滴水兽文创产品在设计过程中存在的问 题, 探讨“滴水兽文化”在创意开发中的潜在可能性， 
以期开辟滴水兽文创设计的新思路、新策略，籍此优 化 “滴水兽文化” 的艺术表达，更好的推广 “滴水兽 文化”。

\section{2. 滴水兽文化的价值分析}

随着时代发展, 生活节奏步伐加快, 各种传统的 工艺美术面临着消亡困境。滴水兽形象留存至今, 得 益于自身浓厚的时代价值, 探讨 “滴水兽文化” 的设 计, 应当从滴水兽的价值内容开始说起。

\section{1 实用价值}

滴水兽的实用价值与闽南地区的建筑风格息息 相关。闽南是中国的主要侨乡之一, 华侨及侨眷总数 占全国的三分之一。闽南地区的移民文化发达, 给文 化交流创造了条件, 且闽南地区有着极强的宗族观念, 追求 “饮水思源, 落叶归根”, 所以即使漂泊海外, 仍怀 “返乡置业” 的期望, 所以在这主客观因素的作 用下，闽南人民将海外的建筑元素带回家乡，与传统 的建筑相结合, 这种中西文化的交融体现在建筑的方 方面面, 包括其中的排水构件。番仔楼开始从无组织 排水转向有组织排水, 即改变原来雨水直接从檐口处 排落至地面的方式, 增设排水系统, 有组织地将雨水 引导至指定的排水处。滴水兽在这套排水系统中, 便 作为排水口, 减少了雨水喷溅墙壁对墙体的损坏, 极 具实用性。

\section{2 精神价值}

在闽南地区，民间信仰浓厚，人们常说是 “三步 一庙宇, 五步一佛堂”, 可见信仰之盛, 因此, 闽南 人民常将各种信仰需求寄托于各式物件之上, 尤其是 以兽类形象作为辟邪的做法得到广泛运用, 常见的有 风狮爷、剑狮、抱鼓石和石狮等, 滴水兽的狮子形象 也有此功效, 除此之外, 不同的滴水兽造型也被寄予 不同的含义, 比如鱼的滴水兽代表着年年有余, 狮子 的滴水兽代表迎福纳祥, 大象表示太平有象、万象更 新, 可爱的狻猊的滴水兽代表迎福纳祥, 麒麟 则有 麒麟送子的寓意, 驾莺代表幸福的象征。“1]这些意 象化的寄托, 让滴水兽具有极高的精神价值。

\section{3 美学价值}

滴水兽的美学价值体现在其种类的多样性和造 型的特殊性上。滴水兽种类繁多, 上文提到主要以兽 类为多, 当然也不乏有石榴、花朵等植物类。如此多 的造型, 给滴水兽的开发提供了系列性条件, 非常适 合运用于视觉设计中。除此之外, 滴水兽自身的造型 独特性也是构成其美学价值的要素之一, 滴水兽的色 彩、纹样、造型都十分考究, 以经典的 “鲤鱼” 形象 为例, 色彩以白色、橙色、黑色、绿色的釉下彩为主, 整体造型圆滑流畅, 是古朴建筑中的一抹亮色, 非常
贴近现代审美中对于 “可爱” 的视觉认知, 给创意设 计提供了很大的空间。

\section{3. 滴水兽文创产品的现状}

随着闽南地区对于文化创意开发的重视, 越来越 多文创人借 “古”创 “新”，参与到在地文化的创意 设计中来。通过对文创市场中的滴水兽文创产品的调 研可知, 滴水兽文创产品的开发主要集中在泉州地区, 开发类型不尽相同, 但总体可划分为两类, 即: 依据 原型的设计和创新组合再设计。

\section{1 依据原型的设计}

由于滴水兽的原生造型就具备充分的美学价值, 因此在滴水兽文创产品的制作上, 利用原型进行同比 例缩放处理是最为常见的创作手法。如 2018 年 “润 物无声” 泉州旅游商品设计创作大赛的金奖作品《掌 中滴水兽》, 就运用这种方法, 取滴水兽中经典的 “金 鱼” 的形象, 在延续传统物件造型的基础上, 进行局 部的艺术处理, 最后产出萌态十足的滴水兽摆件, 产 品本身具有一定的重量, 也可以作为镇纸使用。《掌 中滴水兽》的设计是滴水兽文化开发较为早期的作品, 在后来的设计中, 一些设计团队在此基础上对这一设 计进行功能化处理, 即突出滴水兽尾部弯曲的特点, 将滴水兽身体与尾部连接的区块部分设计成可以置 物的凹槽, 根据凹槽的大小, 产品可以具备笔架、筷 托的功能。同类型的设计还有乐城知礼 (泉州) 文化 创意有限公司设计的 “滴水兽冰箱贴” 产品, 虽然在 设计上有一些创意表现, 但总体的设计方向也是放在 原型的基础上。

\section{2 创意提取再设计}

在滴水兽文创产品的设计上, 除了直接利用原型 的设计开发之外，常见的也有采用创意提取再设计的 方法, 即提炼滴水兽色彩、纹样、造型等核心要素, 加入不同的创意思维进行形象构筑，再运用插画艺术、 刺绣艺术等手法进行再设计, 形成新的创意形象。例 如由泉州府里文化传播有限公司出品, 设计师阿钟设 计的滴水兽系列插画, 就在保留原始滴水兽“金鱼”、

“狮子” 形象的基础上采用创意插画绘制, 并将插画 运用在斗方、挥春、红包等载体之上。同样通过创意 插画形式的有插画师 SHAMS 设计的滴水兽插图, 虽同 为插画作品, 但在产品运用时则有别于寻常的载体, 选择与泉州非遗金苍绣结合, 创作出别具特色的绣品 类文创，样式新颖。

\section{4. 滴水兽设计的不足之处}

2004 年至今, 泉州市旅游局等单位联合主办了 多届的 “泉州旅游纪念品设计大赛” , 参赛作品种 类多样, 具有鲜明的闽南泉州传统文化特色 ${ }^{\mathbf{2} 1}$ 展现 
了诸多取材于滴水兽的优质文创, 但就目前文创市场 上的滴水兽产品来看，仍有许多可改进的空间。

\section{1 概念产品产出少}

闽南地区的文创产品售卖渠道主要集中在景区、 文创商店、文创集市等, 根据对这些地点的走访调研 可以发现, 不论是依据原型进行设计还是对创意元素 提取再设计, 都聚焦于滴水兽的造型本身, 并无过多 延伸的创意, 尽管市面上的滴水兽文创产品中存在精 美的插画形象, 优质的产品载体, 但如若是一味地进 行提取元素, 应用载体的机械设计, 久而久之, 设计 内容就会趋向单薄, 造成产品的同质化。

\section{2 品牌塑造不完全}

“滴水兽文化” 的历史底蕴深, 美学价值高, 但 其作为闽南地域的一个文化分支, 并未有与其文化价 值相匹配的品牌认知度, 通过在淘宝、京东等电商平 台搜索可以发现, 有关滴水兽文创产品的商品词条极 少, 只作为部分文创商店的分支产品展出, 如此一来, 滴水兽文创产品在网络上的曝光度, 或是其品牌性就 得不到保障。追根溯源, 目前闽南地区的文创市场, 没有针对 “滴水兽文化” 进行完全研究开发的文创团 队, 只有部分公司将其作为生产售卖的一环, 即使在 短时间内可以依靠滴水兽的在地文化属性引发闽南 人民的情感共鸣, 但也无法更为深入, 最后导致无法 将文化推广开来的困局。

\section{3 转型定位不明晰}

滴水兽本身具有极高的工艺价值, 在进行精心再 设计的前提下, 将滴水兽作为一件工艺品进行收藏, 以实现对传统技艺的延续, 不失为对传统文化的一 种肯定。 ${ }^{131}$ 因此, 依据目前市面的文创产品来看, 一类是依据滴水兽形象制作的传统工艺美术产品, 价 格昂贵; 一类是经由创意孵化的流行文化创意产品, 价格较低。在这两种类型的产品中, 存在大量设计上 的 “杂糅” , 在文创市场上, 可以经常看到与原型相 同比例的超大摆件, 或是只停留在明信片、钥匙扣等 载体上的浅层设计, 散发出一种劣质的拼凑感, 可见 目前关于文创产品的界定并不明晰, 到底是多一些工 艺美术层面的阳春白雪, 还是多一些文化创意层面的 日用民生, 目前的市场并没能给出一个明确的方向。

\section{5. 滴水兽产品设计新策略}

今年 3 月, 在世界文化和自然双遗产地武夷山, 习近平总书记有感而发。“要推动中华优秀传统文化 创造性转化、创新性发展, 以时代精神激活中华优秀 传统文化的生命力。” 滴水兽作为闽南文化的主要组 成部分, 为推动 “滴水兽文化” 的发展, 应当着重把 握, 促进创新转换, 发掘新的设计策略。

\section{1 挖掘更深层的设计}

滴水兽具有三种特性，即：“实用性”、“精神 性”、“美观性”, 无论是从自身特性出发还是从滴 水兽的历史性出发, 都可以有很好的创意发散, 所以 在设计上, 不应只停留在浅薄的图形运用, 而是可以 探索一些概念性设计, 让产品在具备实用性与美观性 的同时, 也具有一些设计巧思, 与受众产生互动。故 宫 2019 年推出的 “初雪调味瓶” 文创产品, 就搭建 了三个微缩创意场景, 外套玻璃罩, 巧妙地将 “盐” 与 “雪” 进行创意联系, 把把盐装进瓶中, 就会产生 “大学纷纷何所似, 撒盐空中差可拟” 的绝美意象, 从 “初雪调味瓶” 中, 可以看到产品与使用者之间产 生的互动性。在近两年的滴水兽创意开发中, 也有类 似的概念性设计出现在大众视野中。如在 2019 年厦 门设计师 “GuoHuiQing” 在普象 APP 设计师平台发布 的 “鱼吐露一一闽南滴水兽快客杯设计”, 就将滴水 兽的形象融入到闽南地区的茶道文化之中; 2020 年 “润物无声” 泉州文创旅游商品设计创作大赛中, 就 有以滴水兽为主题创作的倒流香台, 名为“云烟成雨”, 这个产品是将滴水兽意象化, 将其形态、功能与道家 思想相结合, 通过倒流香产生的烟雾, 创作出别具特 色的意境。但可能是产品开发尚未完成, 只能在网络 上检索到创意说明, 也期待在未来的文创市场可以看 到这些闪光创意变现落地。

\section{2 塑造更深刻的品牌}

IP 是适应时代发展的新品牌观, 其具有文化母 体、品牌创新和超级符号的属性, 能够通过唤起记忆、 触动情感、实现交流而成为高效的品牌传播载体。 ${ }^{4} \mathbf{1}$ 打造属于滴水兽的个性文化 IP, 可以有效的链接创 意, 使作品更有连续性, 从而增强市场竞争力, 提升 品牌的认知度。围绕 IP 形象来构筑品牌对文创而言 是一种有效的创作思路, 著名的日本当代艺术家村上 隆、奈良美智就通过艺术创作, 创造属于自己的 IP 形象, 在形象中植入创作价值, 风靡全球。文化 IP 可以深化品牌内涵, 泉州艺术家李诗芸就运用这个思 路, 以泉州特色的惠安女形象作为元素, 设计出 HANA （海娜）的文创 IP, 这组产品极大的保留惠安女 “黄 斗笠、花头巾、蓝短衫、银腰链、宽筒裤” 的传统造 型基础, 融入个人审美因素, 延伸出 “国际新潮范”、

“热情洋溢范”、“传统风情范”、“梦幻诗意范”、

“优雅美学范”、“明艳精致范” 这六款不同颜色搭 配的形象, 每个形象都有着属于自己的个性标签, 也 代表了不同的受众群体, 让观众在作品中可以直观自 身, 产生共鸣, 如此一来, 产品就可以很好的转换为 消费内容。滴水兽品类众多, 本身就自带系列性特点, 非常适合作为 IP 形象开发的内容。

\section{3 开发生活化的产品}

文化经济政策和文化创意产业, 要真正生根于地 方文化的资源以及城市的文化实体，即融入地方居民 
的接触、谈话、想法和意见的分享, 进而形塑与生活 形式的特质。1 51 单雯翔院长曾提出一个观点, 文创 不仅仅是产品, 其实更是一种文化精神, 是一种凝练 的精神, 这种精神的基础, 就是要时刻关注社会公众 的文化需求。滴水兽作为一种排水装饰, 本身的文化 属性就具有生活化特点, 更适合从民生日用内容出发 展开设计创作, 但生活化不等于载体 “俗” 化, 生活 化的文创设计不是只有明信片、钥匙扣、冰箱贴, 也 可以产生于衣食住行中。市面上文创食品研发火然泉 达, 洛阳博物馆就打造了 “吃货博物馆” 品牌, 各种 文物设计的棒棒糖、爆米花以其可爱的包装, 出众的 口感迅速出圈。重庆中国三峡博物馆的火锅底料、湖 北省博物馆的睡虎地秦简糕点、苏州博物馆的越窑秘 色瓷莲花碗饼干等都广受好评。今年, 泉州 “润物无 声” 联名款、泉州古城限定的文创雪糕在西街游客服 务中心发售, 有东西塔、钟楼两款文创雪糕, 非常吸 晴。滴水兽文创也可以参考这一思路跟进设计, 在保 持其日用属性的基础上, 遵循 “好设计原则”, 设计 出兼具功能性、美观性、生活化的产品, 以满足人们 的生活需求。

\section{6. 结语}

纵观近年来闽南地区的文创产品设计情况, 可见 “滴水兽文化” 正被逐步焕新, 越来越多的文创人加 入到 “滴水兽文化” 的设计中来。在发展过程中, 为 避免产品设计中良莠不齐的设计情况, 让文化有一个 正确合理的发展方向, 就需要对当下的市场有足够的 了解, 立足于文化, 从消费需求出发, 做出让消费者 喜闻乐见的设计, 以此来优化滴水兽文创的艺术表达, 更好的展现 “滴水兽文化” 之美, 展现 “闽南文化” 之美。

\section{项目基金}

2020 集美大学社会科学校启项目 “基于 设计思维的传统文化创意产品设计研究” (项 目编号: Q202005);

2020 福建省高校哲学社会科学中青年教 师教育科研厅级项目 “设计思维的福建非遗 文化创意产品设计策略研究”（项目编号： JAS20140);

\section{References}

[1]Wang,Z.Zhang,Y.(2018) On monsters -- the function and significance of roof dripping monsters in Southern Fujian architecture. Beauty and the times (City Edition),(04):22-23.

[2]Chen,XJ.(2016)Problems and Countermeasures of Quanzhou element cultural and creative product design. Journal of Quanzhou Normal University,34(01):27-33.

[3]Guo,X.Yao,L.Li,Z.(2018)The Study on Evolution and Protection of Gargoyle in Minnan Traditional Architecture.Modern Urban Research, (01):52-58.

[4]Liu,FL(2019) Value of Traditional Chinese New Year Festival's Characteristic IP to the Communication of Chinese Brand Image.Modern Urban Research. Packaging Engineering, (24): 111-116.

[5]Yuan,YL.Tu,YH(2021) Prospect and Enlightenment of Taiwan's cultural and creative industry. Fujian Arts, (02):23-30. 